\title{
Estimating Discharge of Nitrogen in Zero Water Exchange at I-Sharp Setiu, Terengganu, Malaysia, Based on System Dynamic Approach
}

\author{
Muhamad Safiih Lola* and Anton Abdulbasah Kamil**† \\ *School of Informatics and Applied Mathematics, Universiti Malaysia Terengganu, Kuala Terengganu, Malaysia \\ **Faculty of Economics, Administrative and Social Sciences, Istanbul Gelisim University, Istanbul, Turkey \\ †Corresponding author: Anton Abdulbasah Kamil; akamil@gelisim.edu.tr
}

\section{Nat. Env. \& Poll. Tech.}

Website: www.neptjournal.com

Received: 10-01-2020

Revised: 21-01-2020

Accepted: $16-04-2020$

Key Words:

Nitrogen

System dynamics approach

Sustainability

Zero water exchange

\begin{abstract}
The present study was designed to display the integrated model of nitrogen discharge process (i.e. nitrites and nitrates; ammonia; chlorophyll and dissolved nitrogen, dissolved oxygen) which is part of the complete model of shrimp aquaculture of an Integrated Shrimp Aquaculture Park (i-Sharp) ecosystem in System Dynamic Model Aquaculture-System Policy (SD-AQEP). This study offers a comprehensive elaboration concerning the long-term process of nitrogen accumulation, as well as its effects on shrimp activities. Furthermore, the analysis of the model and the simulation results also show the conditions of nitrogen with several strategies for control and manipulation. For example, in situations where mixing of stock density is high and providing feed into ponds supplies is excessive, the nitrogen dynamic rapidly hits alarming levels. Aforementioned, the typical strategy in this setting such as stocking density and the best time to harvest could be established. Additionally, the model structure represents the discharge derived from the nitrogen process on varied settings of variables in aquaculture development. In conclusion, this model provides an experimental simulation platform that can be implemented by policy makers on long-term strategic management for developing or maintaining large-scale aquaculture development projects in the future.
\end{abstract}

\section{INTRODUCTION}

The marine shrimp aquaculture production has seen a rather rapid increment by 28.5 times from 3,057 tons in 1991 to 87,202 tons in 2010 (Chowdhury et al. 2013). This phenomenal hike, nonetheless, has sparked some disturbing environmental effects due to the aquaculture activities, where water is highly polluted from shrimp effluents. This is because of the shrimp cultured process releases significant amounts of organic matters, nutrients, phytoplankton, and suspended solids where the corresponding shrimp farm practices high quality feeds and promotes high volume of seawater intake (Boyd 1999). Thus, this unsustainable practice adopted by the shrimp industries especially in their methods of managing wastewater has spawn critics and concern previously (Naylor et al. 2000, Hidayah et al. 2016a, Hidayah et al. 2016b, Nobuyuki, et al. 2016, Hidayah et al. 2017).

In general, the ratio for water exchange (WE) daily is below $15 \%$. This is a common practice for the aquaculture industry throughout the nation (Nik Hashim et al. 2013, Khairul et al. 2013, Akeem Babatunde et al. 2018). Herein, risks towards the environment and existing life forms in the water bodies are increased due to the accumulating discharge regurgitated from these aquaculture ponds.
In reality, a large-scale aquaculture project that focuses onto shrimp production setup in Terengganu, Peninsular Malaysia had been initiated by Blue Archipelago Berhad in 2009 known as Integrated Shrimp Aquaculture Park (i-Sharp) (Muhamad Safiih et al. 2016a). This particular project, which is located at Terengganu coastal area of Peninsular Malaysia, reflects a spawning area of a staggering 1,200 hectares (Muhamad Safiih et al. 2016b, Muhamad Safiih et al. 2017). Before the opening of i-Sharp, this project adopted the semi-biofloc system. Nonetheless, only some ponds were exposed to the fully biofloc system at the initial stage. As time progressed, the i-Sharp began focusing on a bio-secure recirculating system via biofloc technology. Some benefits of the biofloc system are that it uses low input seawater and the fact that the system re-circulates water (Zero Water Exchange, ZWE). By implementing the ZWE system, other colossal benefits are achievable, such as high efficiency, sustainable, competitive productivity, and lower feed conversion ratio where major possibilities of achieving to the sustainable management of aquaculture ponds are limited to the efficiency of biofloc system application (Nyan 2011). Besides, as for i-Sharp, water intake from natural sources is initially to fill in and to maintain the level of water in the aquaculture ponds. Such maintenance is undertaken mainly 
to replace the volume of water reduced due to evaporation or filtration. However, only if the effluent can infiltrate natural waterways, such as a river, the remaining trace of cultured water and accumulated residue from the effluent could potentially affect the environment. Unfortunately, organisms like plants and aquatic life forms that exceed the capacity to withstand such changes are surely damaged and turn into environmental pollution. Nevertheless, these remaining sediments and essential wastes could be reprocessed to potentially benefit the agriculture industry (Tanentzap et al. 2015).

With that, nitrogen $(\mathrm{N})$, is a key element associated with the aquatic environment as it functions as one of many variables useful for aquaculture management. Common input of $\mathrm{N}$ comes from the environment, but a study shows that $\mathrm{N}$ in aquaculture farm mainly results from the existing trace of nitrogen in feed used to enhance the growth of aquaculture productions (Thoman et al. 2001). However, as the feeds are digested, the extra non-digestible nitrogen element is excreted; thus, acting as fertilizer that helps in promoting the build-up of planktons and bacteria colonies (Moriarity 1997).

As such, the present study suggests a system dynamic model as the analytical tool in order to develop a conceptual framework useful in combining numerous nonlinear equations with complex feedback. The structural principle of a dynamic system is primarily dominated by the feedback loop structure that forms a central control for all the corresponding systems (Forrester 1968, Muhamad Safiih et al. 2017, Muhamad Safiih et al. 2019). Moreover, the positive feedback is set to keep all variables in an equilibrium state. This equilibrium state acts if any variable(s) in the negative feedback loop is moved from equilibrium to ensure that the system would return to its original state or at least towards a new equilibrium state. This system dynamic model approach analyses the sources of problem behaviour, as well as the feedback structure in the system. Therefore, the primary objective of this study is to build a system dynamic model to simulate the feed of ${ }_{\mathrm{N}}$ in intensive white shrimp (Penaeus vannamei) ponds during culture activities. In addition, the model developed by Burford \& Lorenzen (2004) on Pacific tiger shrimp, Penaeus monod on cultured had been adopted in this study to describe the principal ${ }_{\mathrm{N}}$ transmigrations pro- $^{-}$ cesses, as well as to identify several alternatives to improve yields.

\section{MATERIALS AND METHODS}

\section{Model Description}

The model for discharged nitrogen $\left(_{N}\right)$ represents the production system that reflects increased input of premium feeds and water supply that leads to stacking of nutrient discharged.
Hence, the cultured ponds generate effluents that are rich in chlorophyll-a, suspended solids, nutrients, and toxic waste; which are essential for agar bloom, thus resulting in high biochemical oxygen demand (Paez-Osuna 2001a, 2001b). This study also adopted the dynamic nitrogen model proposed by Burford \& Lorenzen (2004), which had been carried out for intensive cultured of $P$. monodon, along with WE system. With that, the nitrogen dynamic model was applied to describe the complex and the dynamic behaviour of the $\mathrm{N}$ in the monitored ponds. Hence, this study adapted Burford's model to investigate the $P$. vannamei intensive culture that practised ZWE in i-Sharp. The basic model assumption does not require the presence of herbivore (non-plank tonic) in all ponds, where $\mathrm{N}$ input is exclusively from the feed, whereas the growth of shrimp and phytoplankton (or microorganisms) is not hindered due to lack of oxygen or phosphorus. Fig. 1 illustrates the transformation and removal of nitrogen in intensive shrimp pond. The arrows and the boxes represent for key nitrogen $(\mathrm{N})$ components.

The variables embedded in the model are listed in the following: total ammonia, nitrates and nitrites, Chlorophyll-a (phytoplankton), $\mathrm{N}$ in algae biomass, dissolved $\mathrm{N}$ organic, and $\mathrm{N}$ in sediment. Besides, the demand for feed increased the input of $\mathrm{N}$ parallel to the growth of shrimp biomass. Additionally, it was noted that zooplankton, phytoplankton, and nitrifying and heterotrophic bacteria shared the available $\mathrm{N}$ excreted from shrimps in ponds (Burford et al. 2003). However, the accumulation of ammonia first caused a halt in feeding shrimp and then, giving impact on the population mortality (Chen et al. 1990). As for the P. vannamei, the post-larvae (PL) in ecdysis stage dies if the concentration of ammonia exceeds $10 \mathrm{mg} . \mathrm{L}^{-1}$ (Frias-Espericueta et al. 2000). Therefore, if a pond receives an increasing amount

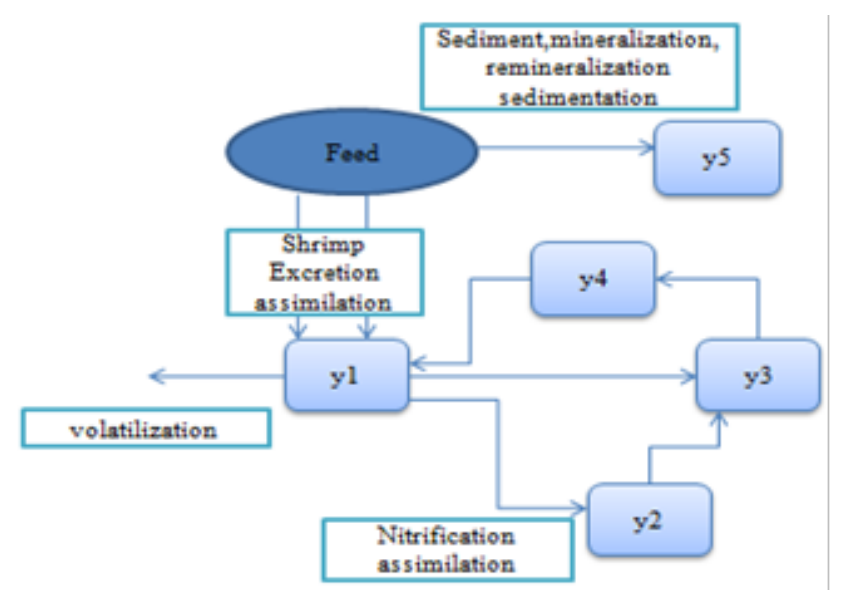

Fig. 1: Nitrogen transformations and removals in intensive white shrimp (Litopenaeus vannamei) 
of feed, the density of phytoplankton would eventually limit its growth via self-shade. Burford \& Lorenzen (2004) predict that the accumulation of ammonia after chlorophyll-a (phytoplankton) impedes its growth. In fact, some $\mathrm{N}$ is lost from the pond due to volatilization of ammonia, particularly due to high $\mathrm{pH}$ periods and heavy aeration.

\section{The Causal Loop Diagram}

The present dynamic model is comprised of causal loop diagrams to represent most of the feedback mechanisms, which is consist of reinforcing/positive feedback loop that is denoted by positive symbol ' + ' or counteract/negative feedback loop that is reflected by negative symbol '-', to depict a change that has taken place in the system variable (Muhamad Safiih et al. 2019). As for this study, the feedback loop functions are a series of cause-and-effect correlated to each other, such that if a change in a given variable or system moves within the loop, it will come back to affect the same variable and other variables. Besides, if an original value or known as 'initials' increase in a variable; the feedback loop in this simulation would eventually result in an expending or increasing effect on the same variable, which is later identified as a 'reinforcing or positive' feedback loop by the system, while the vice versa situation exists if the decreasing effect on the very same variable happens and identified as negative (counteracting or a balancing loop) (Sterman 2002). The positive feedback loop can potentially stimulate volatile exponential growth or cause a collapse in the arrangement of the system associated with simulation behaviour.

Fig. 2 illustrates the causal loop for this study. The concentration of ammonia in the model of discharged nitrogen was fortified by two positive feedback loops that portrayed the processes of nitrates and ammonia. As a result, the negative feedback loops in the system were likely to stabilize the simulation and the asymptotically stable growth, where decaying patterns were observed from the system. Furthermore, the dissolved oxygen (DO) was controlled by two negative feedback loops that represented phytoplankton and shrimp farms. In an instance, increment in ammonia increases the level of nitrates.

The stock-flow diagram in Fig. 3 reflects the core of the discharge of nitrogen model, and it is also the process of quantization and materialization of the causal loop diagram by using Vensim software program (Mesgari et al. 2017). Moreover, based on the stock-flow diagram illustrated in Fig. 3, the related mathematical equation in the mathematical model of system dynamics can be developed.

\section{Basic Model Formulation}

This section discusses the formulations that are afflicted to

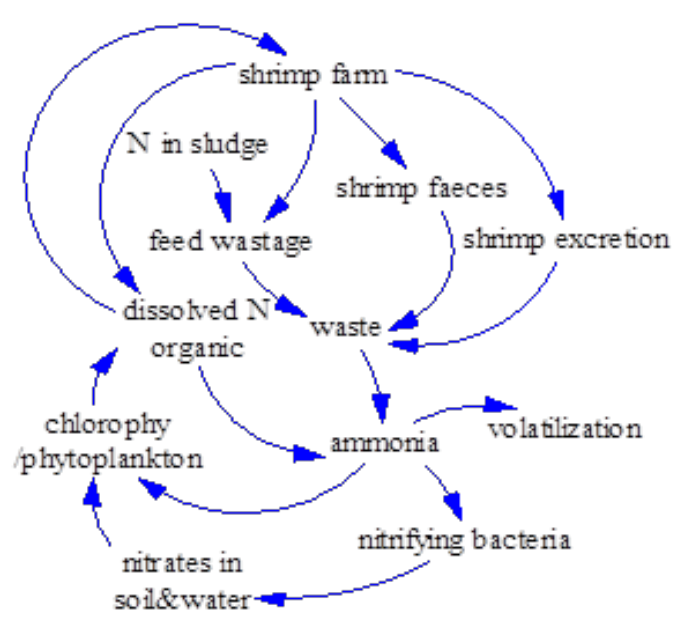

Fig. 2: The causal loop of the discharge of nitrogen model.

several significant model assumptions presented in this study. The mathematical formulations for the discharged nitrogen model in intensive shrimp ponds are derived from the study carried out by Burford \& Lorenzen (2004). Such mathematical modelling incorporates a set of five conjoined differential equations that serve as the main nitrogen components.

Ammonia concentration $\left(x_{1}\right)$

$$
\begin{aligned}
& \frac{d x_{1}}{d t}=q a N_{0} e^{-M t} W t^{b}+r y 4(n+v) x 1 \\
& -\frac{\left.(g \max \text { light }) \frac{x_{1}+x_{2}}{\left(x_{1}+x_{2}\right)+K s n}\right) C x 3 x_{1}}{x_{1}+x_{2}}
\end{aligned}
$$

Nitrites and nitrates $\left(x_{2}\right)$

$$
\frac{d x_{2}}{d t}=n x_{1}-\frac{(g \max \text { light })\left(\frac{x_{1}+x_{2}}{\left(x_{1}+x_{2}\right)+K s n}\right) C x_{3} x_{1}}{x_{1}+x_{2}} \ldots
$$

Chlorophyll-a $\left(x_{3}\right)$

$$
\frac{d x_{3}}{d t}=\left(\frac{(g \max l i g h t) \frac{x_{1}+x_{2}}{\left(x_{1}+x_{2}\right)+K s n}}{x_{1}+x_{2}}\right) x_{3}-s x_{3}
$$

Dissolved N organic $\left(x_{4}\right)$

$$
\frac{d x_{4}}{d t}=s c x_{3}-r x_{4}
$$

$\mathrm{N}$ in sediment $\left(x_{5}\right)$

$$
\frac{d x_{5}}{d t}=(1-q) q a N_{0} e^{-M t} W t^{b}
$$

Where, $x_{1}=\mathrm{NH}_{3}$ concentrations $\left(\mathrm{mg} . \mathrm{L}^{-1}\right), \mathrm{t}=$ time (day): $\mathrm{q}=$ ratio of $\mathrm{N}$ waste released to the water as $x_{1}$ (enters the water as $x_{5}$ ), qaN $\mathrm{e}^{-\mathrm{Mt}} \mathrm{Wt}$ is the total of $\mathrm{N}$ waste input per unit 


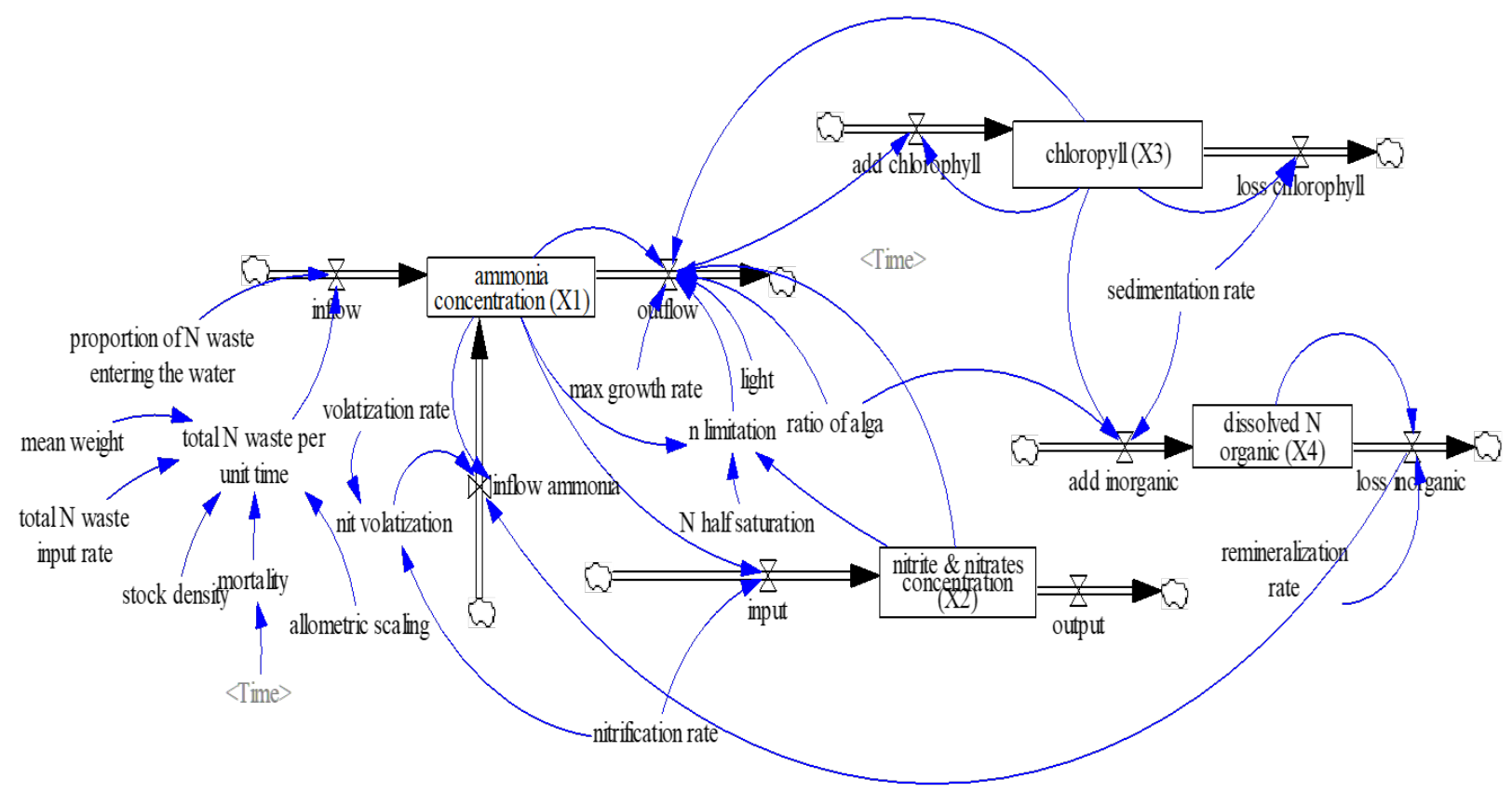

Fig. 3: The stock and flow of the discharge of nitrogen model.

time (mg. $\mathrm{g}^{-1}$ day), $\mathrm{r}=$ re-mineralized rate of $x_{l}$ in sediment $\left(\right.$ day $\left.^{-1}\right), x_{4}=$ weight of $\mathrm{N}(\mathrm{mg})$ in sediment $\mathrm{L}^{-1}$ of aqua-cultured water, $\mathrm{n}=$ nitrification rate $\left(\mathrm{day}^{-1}\right), \mathrm{v}=$ volatilization

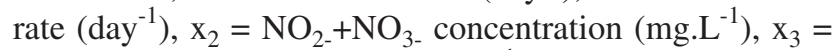
chlorophyll-a concentration (mg. $\mathrm{L}^{-1}$ ) where the concentrations were obtained at a fixed "cN/ $\mathrm{X}_{3}$ ratio of phytoplankton", $\mathrm{s}=$ sedimentation rate of phytoplankton $\left(\mathrm{day}^{-1}\right)$, and $\mathrm{x}_{5}=$ dissolved organic $\mathrm{N}\left(\mathrm{mg} . \mathrm{L}^{-1}\right)$. Besides, the total $\mathrm{N}$ waste input, $\mathrm{aN}_{0} \mathrm{e}^{\mathrm{Mt}} \mathrm{Wt}^{\mathrm{b}}$, had been suggested to be proportional to the metabolism rate of vanamei population (Burford \& Lorenzen 2004); where a is the total $\mathrm{N}$ waste $\mathrm{x}_{1}$ and $\mathrm{x}_{5}$ ) input rate $\left(\mathrm{mg} \cdot \mathrm{g}^{-1} \mathrm{day}^{-1}\right)$, and this parameter was ascertained as the value where $\mathrm{N}$ input over the cycle is equivalent to the total feed $\mathrm{N}$ that is dissimilated to vanamei tissue.

\section{RESULTS AND DISCUSSION}

The preliminary simulation suggests that the maximum weight of shrimp in the cultured pond had been stagnant at $1.63 \mathrm{~g}$, with a stock density of $130 \mathrm{ppL}$ and waste $\mathrm{N}$ input at 2.3. Moreover, the initial values for other variables are listed in Table 1.

Fig. 4 illustrates the simulation behaviour that was obtained during the base run. Since ammonia concentration functioned as a self-counterpoise mechanism controlled by two negative feedback loops, ammonia dissolved of nitrogen organic and chlorophyll eventually attained stability. This controlled the potential of self-increasing ammonia mechanisms using nitrates in water primarily due to the nitrification process. As for the selected cultured, at the end of the simulation, the annual percentage of yield loss due to ammonia concentration had been recorded at $6 \%$. Next, in the second experiment, the stock densities increased to $150 \mathrm{ppL}$ from its initial value; $130 \mathrm{ppL}$. Therefore, increment in stock density decreased inorganic loss. In addition, the increased outflow of ammonia from the pond also helped to activate the first positive feedback loop. The results of these experiments are illustrated in Fig. 5, where it displays ammonia concentrations for both settings, inflow ammonia and outflow ammonia.

\section{CONCLUSION}

The dynamic discharge of nitrogen model offers a generic and comprehensive description concerning the long-term process of feed demand. As a result, the nitrogen input demonstrated an increase as the shrimp biomass grew. Through the integration of nitrates in water; nitrification and loss of inorganic elements into the discharged nitrogen resulted in a comprehensive and systemic model of nitrogen. The model analysis revealed two self-reinforcing, hence, the critical processes of discharge of nitrogen are indeed associated with the content of nitrates in water and nitrification. Furthermore, the ammonia discharges are in effect self-stabilizing. Nevertheless, the ammonia concentrations may play a critical role: if the stock density is high, the total feed waste hikes automatically in a rather rapid manner, and the applied nitrogen $(\mathrm{N})$ is mostly stored in 

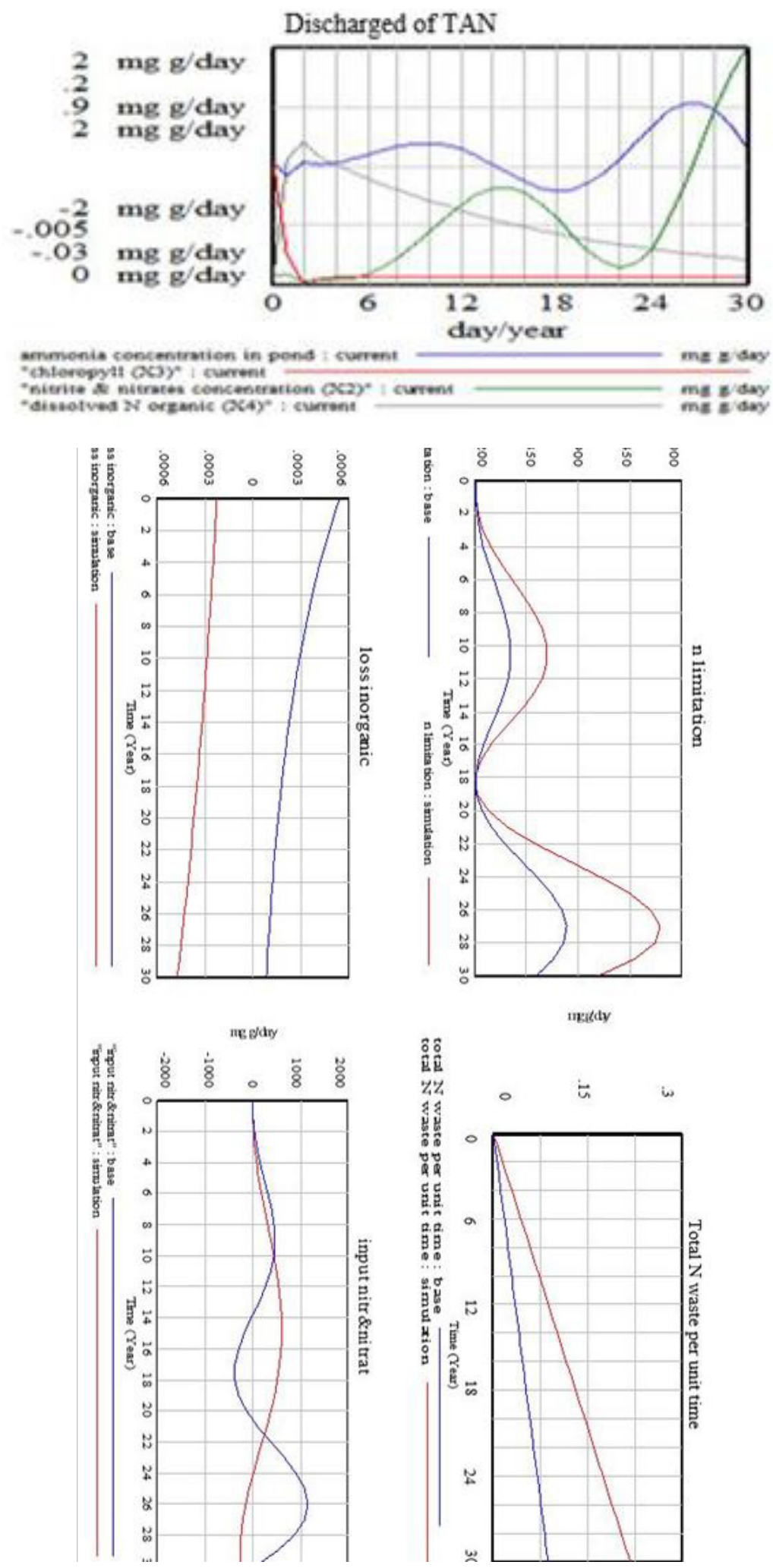

Fig. 4: The base run of the model. 

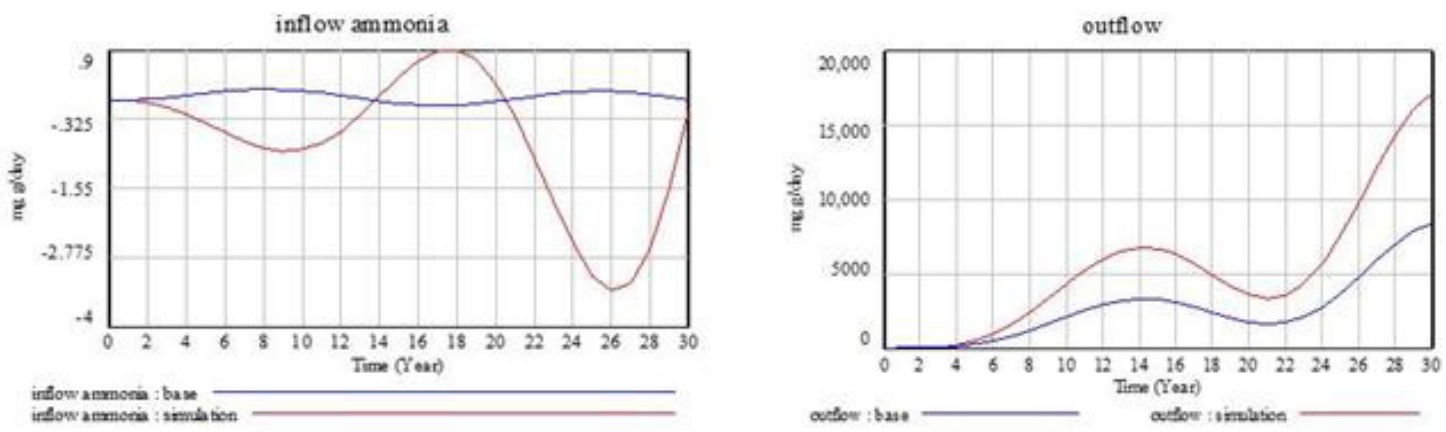

Fig. 5: Inflow ammonia and outflow ammonia simulation.

Table 1: Represent the other parameter value in ponds.

\begin{tabular}{|c|c|c|c|c|}
\hline Parameter description & Symbol & Units & Value & Source \\
\hline \multicolumn{5}{|l|}{ White shrimp population } \\
\hline Shrimp growth coefficient & $K$ & day $^{-1}$ & 0.0086 & Data obtained \\
\hline Shrimp maximum weight & $W$ & G & 16.3 & Data obtained \\
\hline Shrimp stocking weight & $W_{0}$ & G & 6.0 & Data obtained \\
\hline Shrimp mortality & $M$ & day $^{-1}$ & 0.05 & Data obtained \\
\hline Stoking density & $N_{0}$ & shrimp $L^{-1}$ & 130 & Data obtained \\
\hline \multicolumn{5}{|l|}{ Nitrogen dynamics } \\
\hline Waste $N$ Input & $A$ & $m g . g^{-1}$ day $^{-1}$ & 2.3 & Burford \& Lorenzen (2004) \\
\hline Proportion of $\mathrm{N}$ entering as $X_{1}$ & $Q$ & & 0.9 & Burford \& Lorenzen (2004) \\
\hline Allometric scaling of $X_{l}$ excretion & $B$ & & 0.75 & Burford\& Williams (2001) \\
\hline Pond depth & $Z$ & M & 1.2 & Data obtained \\
\hline$N$ half-saturation & $K S N$ & $\mathrm{mg} \cdot \mathrm{L}^{-1}$ & 0.008 & Burford \& Lorenzen (2004) \\
\hline Sedimentation rate & $s$ & day $^{-1}$ & 0.8 & Burford \& Lorenzen (2004) \\
\hline Nitrification rate & $n$ & day $^{-1}$ & 0.15 & Burford \& Lorenzen (2004) \\
\hline Volatilization rate & $v$ & day $^{-1}$ & 0.05 & Burford \& Lorenzen (2004) \\
\hline Sludge remineralization rate & $r$ & day $^{-1}$ & 0.06 & Burford \& Lorenzen (2004) \\
\hline \multicolumn{5}{|l|}{ Phytoplankton parameters } \\
\hline Maximum phytoplankton growth rate & $\operatorname{gmax}$ & day $^{-1}$ & 1.9 & Burford (1997) \\
\hline Ratio surface/saturating light intensity & IO/I sat & & 2.4 & Burford \& Lorenzen (2004) \\
\hline$N / X_{3}$ ratio of algae & $c$ & $\mathrm{~m}^{-1}$ & 13 & Burford \& Lorenzen (2004) \\
\hline Extinction coefficient Non- $X_{3}$ & Kother & & 2.5 & Burford (1997) \\
\hline Extinction coefficient $X_{3}$ & $k X 3$ & $\mathrm{~m}^{-1} \mathrm{mg}^{-1}$ & 14 & Burford (1997) \\
\hline
\end{tabular}

pond populations, particularly for shrimp and phytoplankton. More importantly, the typical feeding system was applied in this setting especially, to control the nitrogen level yields, which led to unprecedented exponentially growing ammonia levels, which also reflected the phytoplankton result for nutrients in the pond system. The model offers an experimental simulation laboratory, where numerous other scenarios and questions pertaining to the long-term discharge of nitrogen could be looked into and analysed. This particular model can also potentially be used by policy makers for long-term sustainability strategic management of large scale aquaculture development projects. The proposed model can also be of interest among students and learners, in teaching and researching environmental sciences, as well as environmental management.

\section{ACKNOWLEDGEMENTS}

This study supported by Niche Research Grant Scheme (NRGS) for Setiu Wetland Development P1(R) (Second Phase) Vote No.: 53131/30, Ministry of Higher Education Malaysia. Acknowledgement for Terengganu Economic Development 
Unit (UPEN), YDSM, Setiu District Welfare and Safety Committee (JKKK) and Setiu Overall Population for providing insights during interview and questionnaire sessions.

\section{REFERENCES}

Akeem Babatunde, D., Ikhsan, N., Murni, K., Mohd Salleh, K. and Armaya'u Hamisu, B. 2018. African catfish aquaculture in Malaysia and Nigeria: Status, trends and prospects. Fisheries and Aquaculture Journal, 9(1): 1-5.

Chowdhury, A.Z., Islam, M.N., Moniruzzaman, M., Gan, S.H. and Alam, M.K. 2013. Organochlorine insecticide residues are found in surface, irrigated water samples from several districts in Bangladesh. Bull. Environ. Contam. Toxicol., 90(2): 149-154.

Boyd, C.E. 1999. Aquaculture sustainability and environmental issues. World Aquaculture, 30(2): 10-13.

Burford, M.A. and Lorenzen, K. 2004. Modeling nitrogen dynamics in intensive shrimp ponds: The role of sediment remineralization. Aquaculture, 229: 129-145.

Burford, M.A., Costanzo, S., Denninson, W., Jackson, C.J., Jones, A.B., Mckinnon, A.D., Preston, N.P. and Trott, L.A. 2003. A synthesis of dominant ecological processes in intensive shrimp ponds and adjacent coastal environments in NE Australia. Marine Pollution Bulletin, 46(11):1456-1469.

Chen, J.C., Liu, P.C. and Lei, S.C. 1990. Toxicity of ammonia and nitrite to Penaeus monodon adolescents. Aquaculture, 89: 127-137.

Forrester, J.W. 1968. Industrial dynamics after the first decade. Management Science, 14(7): 398-415.

Frias-Espericueta, M.G., Harfush-Melendez, M. and Paez-Osuna, F. 2000. Effects of ammonia on mortality and feeding of post larvae shrimp Litopeneaus vannamei. Bulletin of Environmental Contamination and Toxicology, 65: 98-113.

Hidayah, M., Julia Hwei Zhong, M., Nor Azman, K., Suhaimi, S. and Mhd Ikhwanuddin, A. 2016a. Study on carbon sinks by classified biofloc phytoplankton from marine shrimp pond water. Aquaculture, Aquarium, Conservation and Legislation, 9(4): 845-853.

Hidayah, M., Julia HweiZhong, M., NorAzman K. and Mhd Ikhwanuddin, A. 2016b. Biofloc application in closed hatchery culture system of pacific white shrimp, Penaeus vannamei in sustaining the good water quality management. Journal of Fisheries and Aquatic Science, 11(4): 278-286.

Hidayah, M., Julia Hwei Zhong, M., Nor Azman, K., Suhaimi, S. and Mhd Ikhwanuddin, A. 2017. Identification of biofloc microscopic composition as the natural bioremediation in zero water exchange of Pacific white shrimp, Penaeus vannamei, culture in closed hatchery system. Applied Water Science, 7: 2437-2446.

Khairul, A., Rahim, A., Yuzine, E. and Aziz, A. 2013. The influence of alien fish species on native fish community structure in Malaysian waters. Kuroshio Science, 7(1): 81-93.

Mesgari, I., Jabalameli, M. S. and Barzinpour, F. 2017. System dynamics modeling for national agricultural system with policy recommenda- tions: Application to Iran. Pakistan Journal of Agricultural Sciences, 54(2): 457-466.

Muhamad Safiih, L., Siti Hanani, I., Mohd Noor Afiq, R. and Mhd Ikwanuddin, A. 2016a. Forecasting towards planning and sustainable development based on a system dynamic approach: A case study of the Setiu District, State of Terengganu. Open Journal of Statistics, 6(5): 931-950.

Muhamad Safiih, L., Mohd Noor Afiq, R., Mohd Naeim, A.R., Mhd Ikhwanuddin. A., Madzli, A. H., Syerrina, Z. and Marzuki, I. 2016b. A system dynamics model for analyzing the eco-aquaculture system with policy recommendations: Case study on Integrated Aquaculture Park (i-Sharp), Setiu Terengganu. AIP Conference Proceedings, AIP Publisher.

Muhamad Safiih, L., Siti Hanani, I., Mohd Noor Afiq, R. and Mhd Ikwanuddin, A. 2017. Sustainability of integrated aquaculture development project using system dynamic approach. Journal of Sustainability Science and Management, 12(2): 194-203.

Muhamad Safiih, L., Mohd Noor Afiq, R., Mohd Fadli, H., Mohd Tajuddin, A., Kamil, A. A., Izham, M. Y., Yahaya, I. and Nur Zafirah, A.K. 2019. Sustainable development of Tasik Kenyir eco-tourism using system dynamics. In: Mohd Tajuddin, A., Aqilah, M., Mohamed, N.Z., and Muhamad Safiih, L. (eds.) Greater Kenyir Landscapes, p. 257-270. Cham, Switzerland: Springer Nature.

Moriarity, D.J.W. 1997. The role of microorganisms in aquaculture ponds. Aquaculture, 151: 333-349.

Naylor, R.L., Goldburg, R.J., Primavera, J.H., Kautsky, N., Bevridge, M.C.M., Clay, J., Folke, C., Lubachenco, J., Mooney, H. and Troell, M. 2000. Effect of aquaculture on world fish supplies. Nature, 405: $1017-1024$

Nik Hashim, N. M., Azlina, A. A. and Nik Mohd, H. H. 2013. Technical efficiency in aquaculture industry using Data Envelopment Analysis (DEA) window: Evidences from Malaysia. Journal of Sustainability Science and Management, 8(2): 137-149.

Nobuyuki Kawasaki, M.R.M., Kushairi, N. N., Fatimah, Y., Akio, I. and Ayato, K. 2016. Release of nitrogen and phosphorus from aquaculture farms to Selangor river, Malaysia International Journal of Environmental Science and Development, 7(2): 113-116.

Nyan, T. 2011. Intensive shrimp culture water management: Biofloc technology and waste water treatment system. Persidangan Tahunan MANCID ke 16 (16 ${ }^{\text {th }}$ MANCO). Penang.

Paez-Osuna, F. 2001a. The environmental impact of shrimp aquaculture: causes, effects and mitigating alternatives. Environmental Management, 28: 131-140.

Sterman, J.D. 2002. System Dynamics: Systems thinking and modeling for a complex world. Working Paper Series, Massachusetts Institute of Technology, Engineering Systems Divisions.

Tanentzap, A.J., Lamb, A., Walker, S. and Farmer, A. 2015. Resolving conflicts between agriculture and the natural environment. PLoS Biology, 13(9): 1-13.

Thoman, E.S., Ingall, E.D., Davis, D.A. and Arnold, C.R. 2001. A nitrogen budget for a closed, recirculating mariculture system. Aquacultural Engineering, 24: 195-211. 